\title{
Effect of application of edible coating and packaging on the quality of pansies (Viola $\times$ wittrockiana) of different colors and sizes
}

\author{
Luana Fernandes ${ }^{1,2,3}$, José A Pereira ${ }^{1}$, Paula Baptista ${ }^{1}$, \\ Jorge A Saraiva $^{3}$, Elsa Ramalhosa ${ }^{1}$ and Susana Casal ${ }^{2}$
}

\begin{abstract}
The effects of alginate edible coating on the quality of pansies (visual appearance, weight loss, water activity, color, and dimensions change) were studied during refrigerated storage $\left(4^{\circ} \mathrm{C}\right)$. The role of pansies' color and size, as well as packaging, was also studied. Alginate treatments resulted in a beneficial effect on the visual appearance of pansies under refrigerated storage when compared to the uncoated, delaying their degradation from 3-4 days up to 14 days, depending on the pansies' color, probably derived from their different petal thicknesses (83 to $183 \mu \mathrm{m}$ for yellow and red pansies). The unpackaged coated pansies had different behaviors during storage, associated with their dimensions (the larger coated pansies maintained good visual appearance during longer storage times than the smaller ones). However, the packaged pansies treated with edible coating showed to have lower weight loss and shrinkage than the unpackaged, irrespective of the color and size, with physical stability up to 14 days. In summary, the cumulative use of alginate coating with packaging under refrigerated storage may contribute to extend pansies' shelf life.
\end{abstract}

\section{Keywords}

Flowers, alginate coating, cold storage, visual appearance, shelf life

Date received: 15 March 2017; accepted: 19 December 2017

\section{INTRODUCTION}

The demand for edible fresh flowers has increased in recent years due to the growing interest of consumers and professional chefs. Pansies (Viola $\times$ wittrockiana) are attractive edible flowers, with a colorful pallet of options, rich in health-promoting compounds such as anthocyanins, carotenoids, flavonoids, potassium, and phosphorus, and showing interesting in-vitro antioxidant and free radical-scavenging properties (Gamsjaeger et al., 2011; Rop et al., 2012; Vukics et al., 2008). However, edible flowers have a limited shelf life and are very delicate, being highly susceptible to petal abscission, discoloration, wilting, dehydration, and browning soon after harvest. Several strategies

Food Science and Technology International 0(0) 1-9

(C) The Author(s) 2018 Reprints and permissions:

sagepub.co.uk/journalsPermissions.nav

DOI: $10.1177 / 1082013217753229$

journals.sagepub.com/home/fst

๑SAGE have been tentatively used to improve postharvest storage of fresh pansies, including refrigerating, drying or canning in sugar, or preserving in distillates. However, these methods may cause undesirable biochemical and nutritional changes in the final product that may affect its overall quality. Therefore, finding suitable methods for preserving the quality of pansies is extremely important. Until now, few studies on the postharvest

\footnotetext{
${ }^{1}$ Centro de Investigação de Montanha (CIMO)/School of Agriculture, Polytechnic Institute of Bragança, Portugal

${ }^{2}$ Faculty of Pharmacy, LAQV@REQUIMTE/Laboratory of Bromatology and Hydrology, Porto University, Portugal

${ }^{3}$ Organic Chemistry, Natural Products and Agrifood (QOPNA) Chemistry Department, Aveiro University, Portugal

Corresponding author:

Elsa Ramalhosa, Centro de Investigação de Montanha (CIMO)/ School of Agriculture, Polytechnic Institute of Bragança, Campus de Santa Apolónia, 5300-253 Bragança, Portugal.

Email: elsaramalhosa@ipb.pt
} 
preservation of pansies have been done. Kelley et al. (2003) had studied the effect of temperature $(-2.5$ to $20^{\circ} \mathrm{C}$ ) on pansies and showed that only the storage at 0 and $2.5^{\circ} \mathrm{C}$ maintained the visual quality of pansies for two weeks, which decreased drastically when higher temperatures were used. Edible coatings are a recent technology used in fruits and vegetables and reported to have the potential to improve food appearance and prolong their shelf life (Alboofetileh et al., 2014; Alvarez et al., 2013; Contreras-Oliva et al., 2012; Li et al., 2012). However, the few studies on edible flowers coating performed until now have focused on broccolis (Alvarez et al., 2013; Ansorena et al., 2011; Moreira et al., 2011), all studies using chitosan as the main polysaccharide. Alginate coating, extensively used on fruits and vegetables, such as lettuce (Tay and Perera, 2004), apple fresh cut (Moldão-Martins et al., 2003), carrot (Amanatidou et al., 2000), and mushroom (Hershko and Nussinovitch, 1998), has never been used in edible flowers. Furthermore, alginate coatings are reported to possess good film-forming properties, producing uniform, transparent, and water-soluble films (Lin and Zhao, 2007). They also improve the coating adhesion to the surface of vegetables (Fisher and Wong, 1972), are good oxygen barriers (Conca and Yang, 1993), and reduce the weight loss and natural microflora counts (Amanatidou et al., 2000). Even though alginate is not such a good barrier to water loss as chitosan, it can surpass the allergy problem that some sensitive persons have to seafood, from which chitosan is extracted.

To our knowledge, until now, there is no available scientific literature about the use of edible coatings for maintaining the quality and extending the shelf life of pansies. In this order, the objective of this study was to evaluate for the first time the effect of alginate-based edible coatings on the quality of pansies during storage under refrigeration $\left(4^{\circ} \mathrm{C}\right)$, with and without packaging. The quality of pansies, of different colors and sizes, was evaluated in relation to some physicochemical characteristics, namely, visual appearance, color, water activity, and weight loss.

\section{MATERIAL AND METHODS \\ Samples}

Fresh pansies (Viola $\times$ wittrockiana) with different colors (red, white, violet, and yellow) were collected in full ripening state on October 2016 at the greenhouse of the School of Agriculture, Polytechnic Institute of Bragança (Bragança, Portugal). The degree of edible flower full ripeness was determined on the basis of the flowers' size, opening, and color (Rop et al., 2012). After harvest, fresh flowers were immediately transported to the laboratory under refrigeration.

\section{Edible coatings application}

Edible coating treatment was applied according to the method used by Tay and Perera (2004). Pansies were immersed in $0.5 \%$ alginate (Panreac Química SA, Barcelona, Spain) from brown algae solution (w/v) (made with sterile distilled water) for $30 \mathrm{~min}$. Residual alginate solution was allowed to drain for $5 \mathrm{~min}$ before immersing the samples in $1 \% \mathrm{CaCl}_{2}$ solution $(\mathrm{w} / \mathrm{v})$ for $30 \mathrm{~min}$ to induce spontaneous cross-linking reactions. Surface water was carefully blotted as before, using paper towels.

\section{Storage assays}

In the first experiment, fresh and coated pansies of four colors (white, yellow, red, and violet) were stored under refrigeration $\left(4^{\circ} \mathrm{C}\right)$, until presenting unsatisfactory visual appearance. Every day, at the same time, photos of the flowers were taken and the water activity, weight loss, dimensions, and color were measured, as detailed below.

In the second experiment, two factors were studied during pansies' storage, namely, size and the role of packaging. To perform this experiment, pansies of two colors (white and violet), with three different sizes (small, medium, and large), were used and analyzed in terms of the same parameters mentioned previously. The criterion used to define the size was the following: small: $<3.5 \mathrm{~cm}$; medium: between 3.5 and $4.5 \mathrm{~cm}$; and large: $>4.5 \mathrm{~cm}$ (regarding width or length). Pansies with different sizes were divided into two groups: one group was left inside Petri dishes while the second group was packed in thermosealed plastic bags (polyamide and polyethylene) (Alfa, Spain). Each experiment was performed on six flowers $(n=6)$.

\section{Color, dimensions, water activity, and weight loss}

Flowers' color was evaluated in different parts of the pansies' petals, with a colorimeter Minolta CR-400 (Osaka, Japan), using CIELab scale, namely, $L^{*}, a^{*}$, and $b^{*}$ coordinates, where $L^{*}$ varies between 0 (black) and 100 (white), $a^{*}$ (- green to $\mathrm{red}^{+}$), and $b^{*}$ ( ${ }^{-}$blue to yellow $\left.{ }^{+}\right)$. Furthermore, the Chroma $\left(C^{*}\right)$ and Hue Angle $\left(h^{*}\right)$ values were determined. In order to analyze color changes due to edible coating treatment, total color difference $\left(\Delta E^{*}\right)$ was also calculated according to the following equation

$$
\Delta E^{*}=\sqrt{\left(\Delta L^{*}\right)^{2}+\left(\Delta b^{*}\right)^{2}+\left(\Delta a^{*}\right)^{2}}
$$

where $\Delta$ was the difference of the parameters' values after the edible coating treatment and before it (fresh sample, day 0 ). 
Width and length of pansies were measured with a digital caliper (Powerfix, Berlin, Germany). To measure these dimensions, the flowers were positioned with the darkest petals down. Water activity was determined with a portable water activity meter (Novasina, LabSwift-aw, Lachen, Switzerland). This parameter was evaluated on three samples before treatment (control) and on all samples after edible coating treatment.

Weight was measured in a digital balance (Kern ACJ/ACS, Balingen, Germany).

Weight loss (WL) was determined according to equation (2)

$$
W L=\frac{M_{0}-M}{M_{0}} \times 100
$$

where $M_{0}$ is the initial mass of fresh pansies before edible coating treatment and $M$ is the mass of pansies after edible coating application.

\section{Microscopic analysis of pansies' petals}

Fresh petals of different colors were dehydrated by passing them through increasing concentrations of ethanol $(70,80,90$, and $100 \%)$ for $4 \mathrm{~h}$ each and then placed in paraffin to fix. Thin sections of the petals were then cut into random transversal sections, mounted in water, and observed on a light microscope equipped with a camera (Fotocamere Leica DFC49012, Heerbrugg, Switzerland). Petals' thickness was measured in different points (minimum 36 times) on three flowers.

\section{Statistical analysis}

The SPSS Statistical software, v. 18.0 (SPSS Inc., Chicago, IL), was used for the statistical treatment of the data. The normality of the data was verified by Shapiro-Wilk test. Analysis of variance (ANOVA) or ANOVA Welch were carried out to determine if there were significant differences $(\mathrm{p}<0.05)$ between samples, depending on the existence or not of homogeneity of variances. Additionally, if significant differences were detected between treatments, a post hoc analysis was performed, namely, Tukey's honestly significant difference test if variances in the different groups were identical or Games-Howell test if they were not. The homogeneity of the variances was tested by Levene's test.

\section{RESULTS AND DISCUSSION \\ Effect of edible coating on pansies' characteristics during storage}

Visual appearance: Uncoated and coated. Figure 1 shows changes during the storage of the uncoated and coated pansies. Yellow uncoated pansies showed good appearance until three to four days, while red uncoated pansies presented a good appearance until six days of storage. After this period, the borders of the petals started to shrivel. When alginate coatings were applied, better results were observed. All pansies (white, yellow, violet, and red) maintained a similar appearance to fresh flowers until six days. After six days, the darker flowers (violet and red) maintained best appearance than lighter flowers (white and yellow). In fact, the darkest flowers maintained similar appearance to fresh ones until 12 days, in opposition to the lighter ones that shrank after six days. These results are very promising because the shelf life almost doubled.

When comparing uncoated and coated pansies, application of edible coatings increased their shelf life irrespective of the pansies' color. Furthermore, edible coatings may behave as a protective barrier and consequently being able to reduce respiration and transpiration rates through flower surfaces, retard microbial growth, and color changes (Ansorena et al., 2011; Meneghel et al., 2008). Specifically regarding alginate use, Nussinovitch and Hershko (1996) observed that alginate coatings served as a barrier to moisture loss in garlic and later Hershko and Nussinovitch (1998) found that coated mushrooms have better appearance and color, as well as an advantage in weight variations, in comparison with uncoated mushrooms.

Weight loss, water activity, dimensions, and color. Weight loss (\%), water activity, width $(\mathrm{cm})$, and length $(\mathrm{cm})$ of the coated pansies along storage compared to fresh uncoated pansies are shown in Figure 2(a) to (d). Concerning weight loss (Figure 2(a)), some differences were found among pansies with different colors: red and violet pansies presented consistently lower weight loss than yellow and white ones. After 12 days of storage, white and yellow pansies had the highest values of weight loss, with yellow $(68.6 \%)$ and white $(66.8 \%)$ pansies losing almost twice the weight compared to red pansies $(32.5 \%)$. These severe losses are undesirable because it will mean a loss of economic revenue and has a strong impact on the appearance of the final product, due to shrinkage. It must be again mentioned that by using fresh uncoated pansies as references, negative weight loss were obtained in the first days of storage due to the weight gain imposed by the incorporation of alginate to the surface of the coated pansies.

Even though a decrease in water activity values was observed after the application of edible coatings to pansies with different colors during storage, the measured values remained quite similar to those of fresh flowers $(0.980 \pm 0.005)$ (Figure 2(b)). 


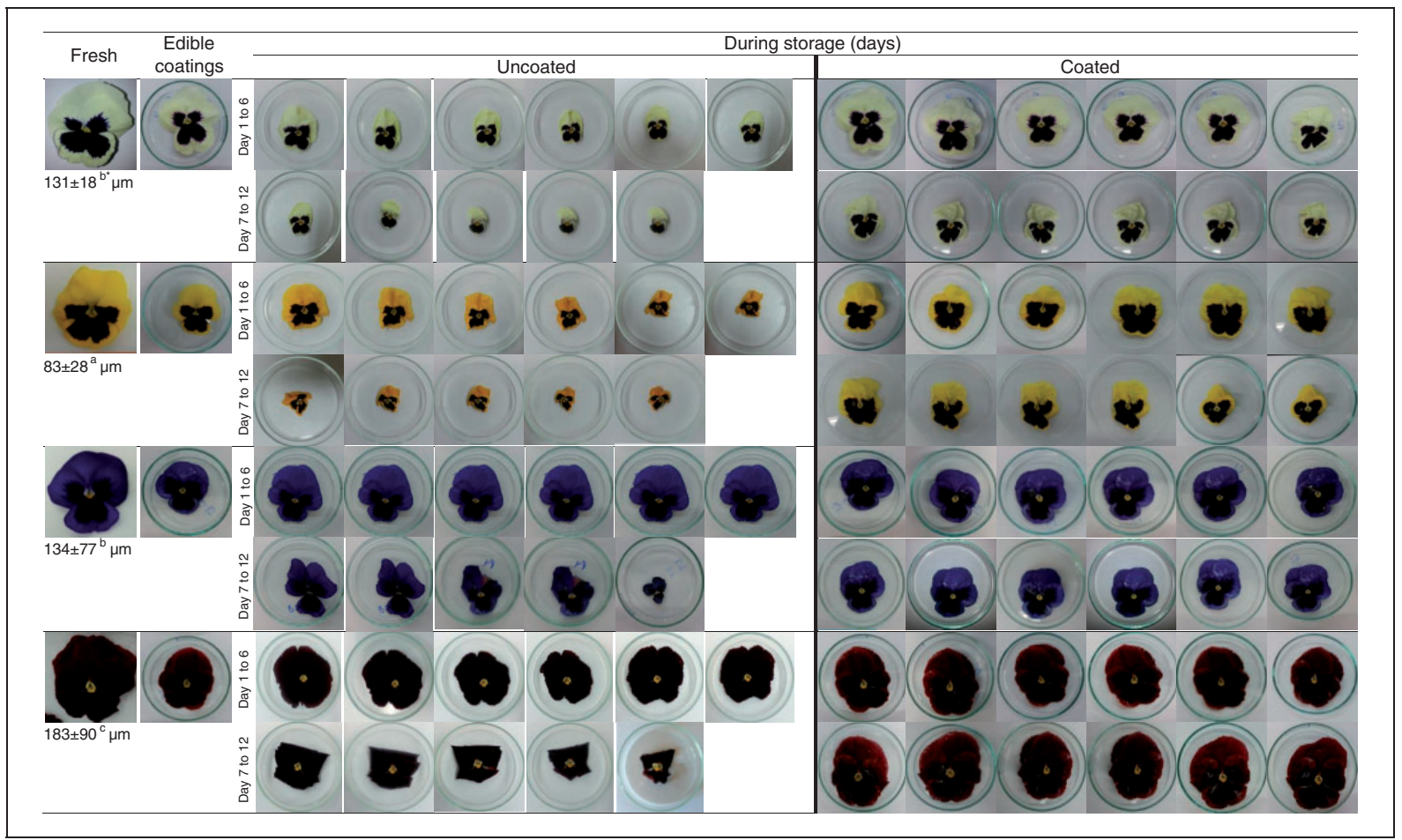

Figure 1. Visual appearance of pansies (white, yellow, violet, and red) in fresh, uncoated and after applying edible alginate coating, during refrigerated $\left(4^{\circ} \mathrm{C}\right)$ storage $(n=3)$. Average values of petals' thickness $(\mu \mathrm{m})$ are also presented. *Petals' thickness (um). Values with the same letter are not statistically different $(p>0.05)$.

Regarding the width and length, all pansies treated with edible coating reduced their dimensions during storage (Figure 2(c) and (d)); however, red pansies showed a lower reduction, when compared with the other pansies. After 12 days of storage, yellow and white pansies decreased their size to half, namely, width reductions from $5.0 \pm 0.2$ to $2.5 \pm 0.2$ and from $5.0 \pm 0.2$ to $3.0 \pm 0.1 \mathrm{~cm}$, respectively, and length reductions from $6.1 \pm 0.3$ to $2.6 \pm 0.4$ and from $6.1 \pm 0.3$ to $3.2 \pm 0.5 \mathrm{~cm}$, respectively.

Total color variation $\left(\Delta E^{*}\right)$ of the coated pansies during storage is shown in Table 1. In general, all pansies showed no significant differences $(\mathrm{p}<0.05)$ up to 12 days of storage. Nevertheless, after the application of edible coatings, pansies treated with alginate ( 0 days) showed appreciable differences to the human eye compared to fresh pansies ( $\Delta E^{*}$ of up to three units as suggested by Trivellini et al. (2014)). This can be explained because after the application of edible coating, the flowers become brighter, as a result of the formation of the film around the flower. In our opinion, this fact is not undesirable but in future, sensory analyses must be performed in order to evaluate the acceptability or even the preference of consumers.

Thickness of pansies' petals of different colors. Thickness of the fresh pansies' petals was measured in order to understand if pansies with different colors (white, yellow, violet, and red) had petals with different thickness, explaining in part the results obtained during their storage and shelf life. To our knowledge, these are the first results pertaining to the thickness of pansies' petals. Our data showed that yellow pansies had significantly $(\mathrm{p}<0.05)$ thinner petals than other colors (Figure 1), ranging from 47 to $141 \mu \mathrm{m}$. On contrary, red pansies had thicker petals (ranging from 62 to $357 \mu \mathrm{m}$ ), while white and violet pansies showed petals with intermediate values, without significant differences between them. These results are very interesting and may explain why red pansies showed lower weight loss, maintained their dimensions, and showed good visual appearance during longer storage times. Their higher thickness may improve their barrier against exchanges with the exterior, since flowers are generally characterized by active metabolism, even during refrigerated storage (Cevallos and Reid, 2000). On the contrary, yellow flowers showed the highest weight and dimension loss, probably because their petals were thinner, leading to lower resistance.

\section{Effect of edible coatings and packaging on pansies with different sizes}

In this section, we studied the effect of pansies' size and the role of packaging. White and violet pansies were chosen to perform the experiments because they are 


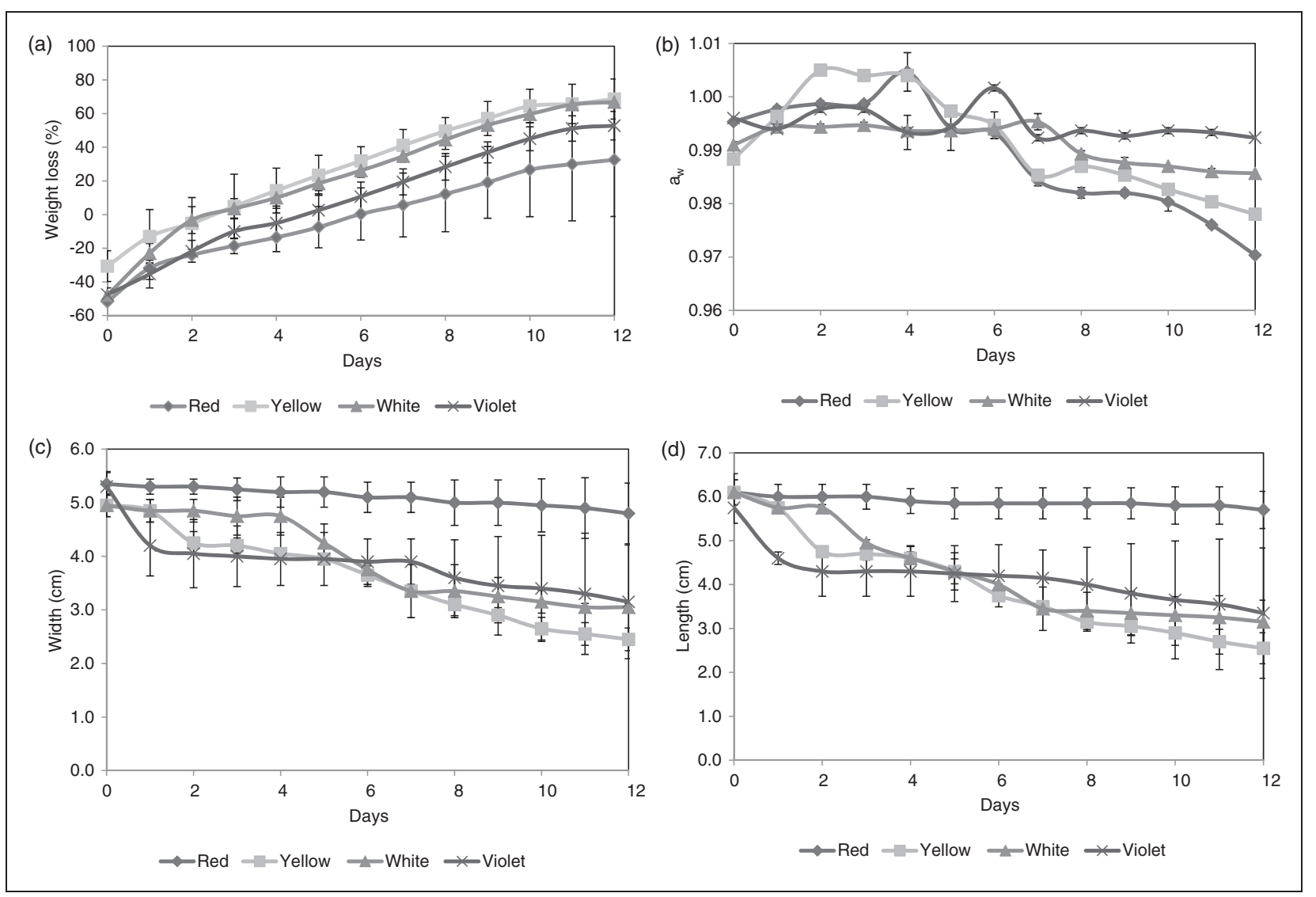

Figure 2. Treated pansies with edible coatings during refrigerated $\left(4^{\circ} \mathrm{C}\right)$ storage: (a) weight loss (\%),(b) water activity $\left(a_{w}\right)$, (c) width $(\mathrm{cm})$, and $(d)$ length $(\mathrm{cm})$. Values are expressed as: mean \pm standard deviation $(n=3)$.

Table 1. Total color difference $\left(\Delta E^{\star}\right)$ of pansies (yellow, white, red, and violet) treated with alginate during storage in comparison to the uncoated (fresh, $\mathrm{t}=0$ days) pansies

\begin{tabular}{|c|c|c|c|c|c|c|c|}
\hline \multirow[b]{2}{*}{ Days } & \multicolumn{2}{|l|}{ Yellow } & \multicolumn{2}{|l|}{ White } & \multirow[b]{2}{*}{ Red } & \multicolumn{2}{|l|}{ Violet } \\
\hline & Light part & Dark part & White part & Violet part & & Light part & Dark part \\
\hline 0 & $23.9 \pm 1.4 \mathrm{a}$ & $21.3 \pm 17.1 \mathrm{a}$ & $6.6 \pm 2.7 a$ & $24.6 \pm 18.2 a$ & $12.4 \pm 0.8 a$ & $3.3 \pm 0.6 a$ & $23.7 \pm 18.9 b$ \\
\hline 3 & $31.0 \pm 5.7 b$ & $24.2 \pm 15.6 a$ & $6.5 \pm 1.1 \mathrm{a}$ & $19.7 \pm 3.8 a$ & $15.0 \pm 8.2 a$ & $15.1 \pm 7.2 b$ & $8.9 \pm 3.3 a, b$ \\
\hline 5 & $32.5 \pm 5.2 b$ & $26.5 \pm 16.3 a$ & $6.1 \pm 1.4 a$ & $33.2 \pm 18.0 \mathrm{a}$ & $15.4 \pm 8.2 \mathrm{a}$ & $6.2 \pm 1.0 \mathrm{a}$ & $9.0 \pm 5.2 a, b$ \\
\hline 9 & $31.4 \pm 2.0 b$ & $21.8 \pm 11.8 a$ & $7.4 \pm 3.2 \mathrm{a}$ & $22.1 \pm 12.8 a$ & $18.1 \pm 5.4 a$ & $14.0 \pm 0.2 b$ & $8.0 \pm 1.1 \mathrm{a}$ \\
\hline 12 & $32.7 \pm 0.9 b$ & $27.9 \pm 17.7 a$ & $7.6 \pm 2.8 a$ & $31.4 \pm 22.5 a$ & $19.3 \pm 6.1 \mathrm{a}$ & $6.8 \pm 0.8 a$ & $10.2 \pm 5.4 a, b$ \\
\hline
\end{tabular}

Notes: Values are expressed as: mean \pm standard deviation. Values with the same letter in same column are not statistically different $(p>0.05)$.

the most consumed, while having simultaneously two colors that showed opposite behaviors in the previous study.

Visual appearance. Figure 3 shows the appearance of the coated pansies of different sizes (large, medium, and small) during storage, with or without plastic packaging. Regarding the packaged coated flowers, its appearance (color and size) kept constant up to 14 days of storage, while the unpackaged coated flowers showed more undesirable changes, shrinking rapidly, in accordance with the previous study. Moreover, fresh flowers of smaller sizes were spoiled easier than the larger ones, while these size-induced differences were not perceived in the packaged flowers. By observing Figure 3, it is clear that after seven days of storage, 


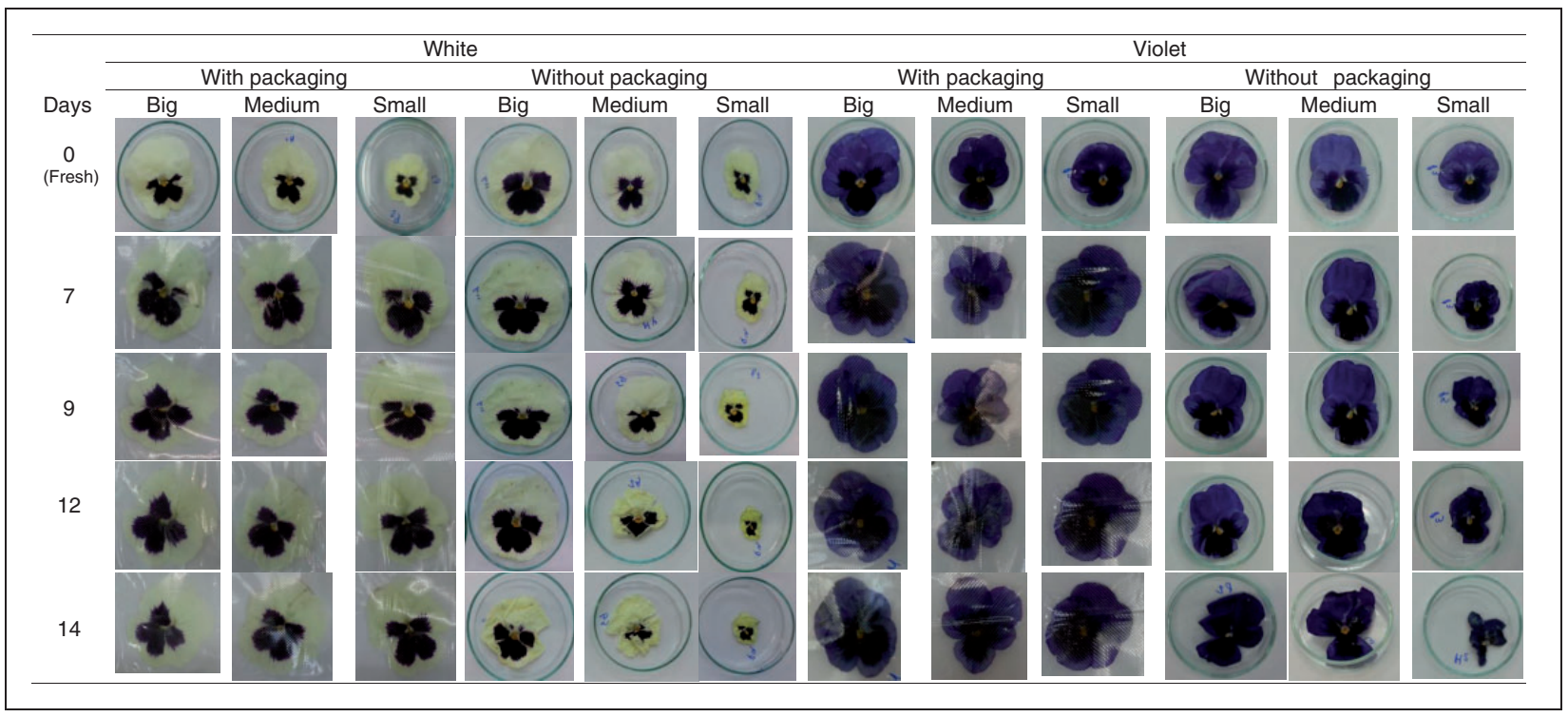

Figure 3. Visual appearance of pansies (white and violet) of different sizes (small, medium, and large), with or without plastic packaging, before and after applying edible coatings during storage.

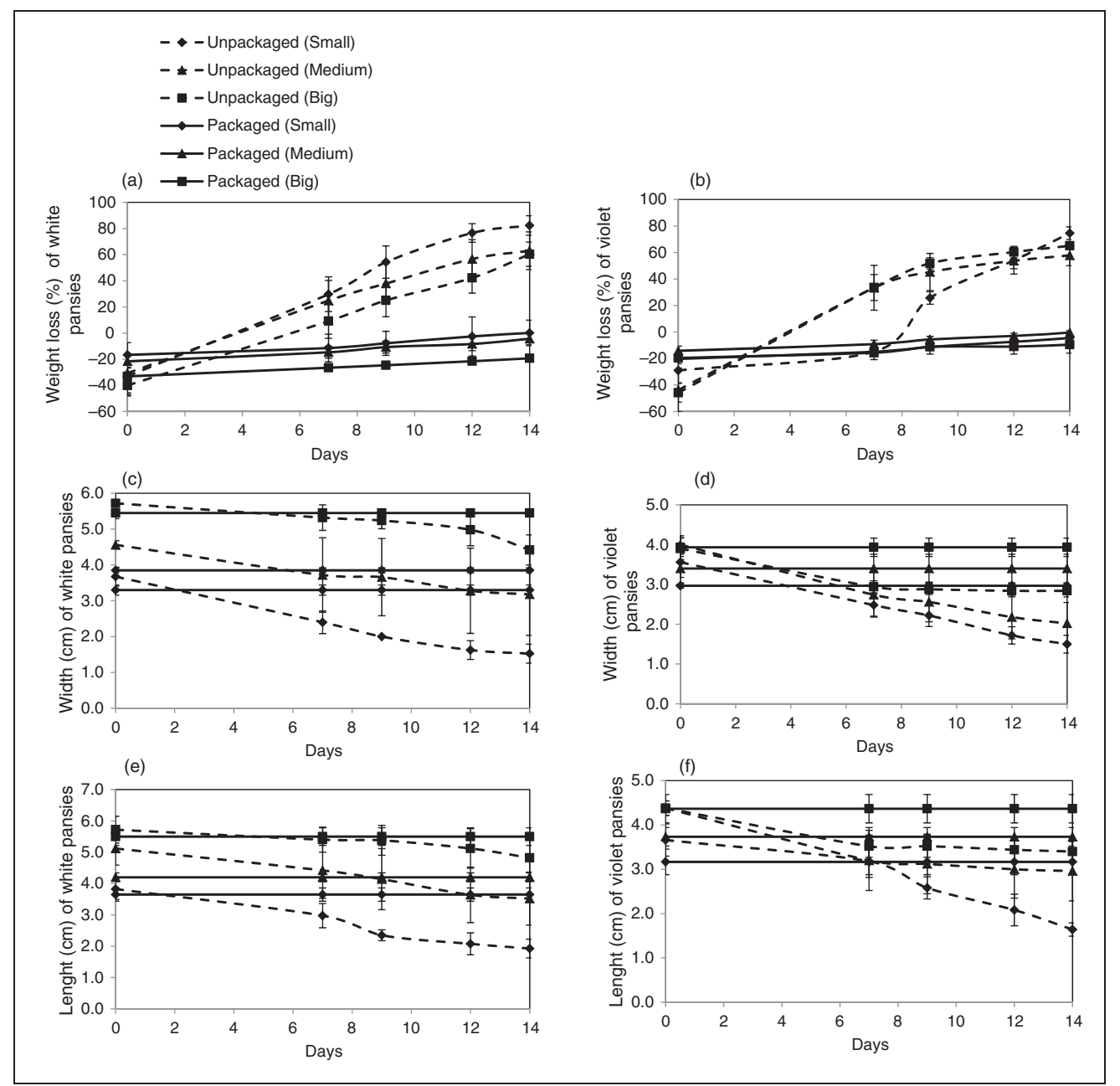

Figure 4. Packaging effect during refrigerated $\left(4^{\circ} \mathrm{C}\right)$ storage of the coated pansies of different sizes on: (a) and $(\mathrm{b})$ weight loss (\%), (c) and (d) width (cm), and (e) and (f) length (cm), of white and violet pansies. 


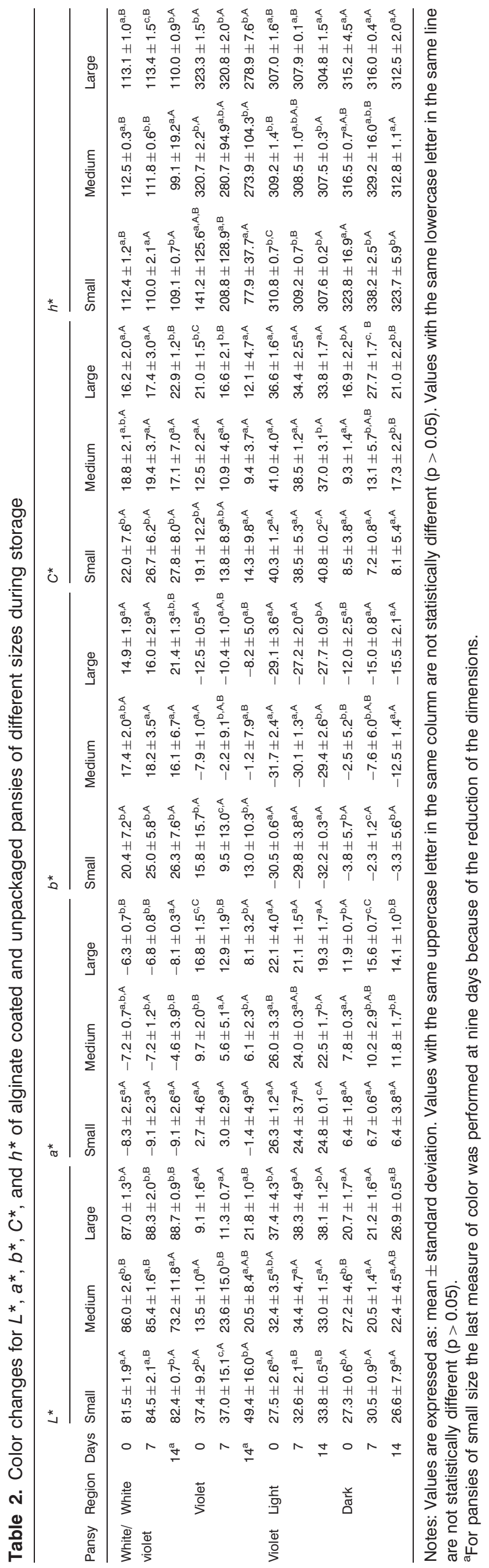


the smaller flowers were dry and shriveled, while the larger flowers had a better appearance for longer storage periods. Furthermore, violet pansies seemed to keep better appearance than the white pansies, in line with the previous results.

Weight loss, dimensions, water activity, and color. The weight loss of the coated pansies of different sizes along storage is detailed in Figure 4 (Figure 4(a) and (b) for white and violet pansies, respectively), with and without packaging. After 14 days of storage, the unpackaged pansies presented the highest weight loss. Among sizes, the smaller pansies were the most affected ones, decreasing the weight in average 82 and $75 \%$ in white and violet pansies, respectively. On the contrary, the packaged pansies maintained their weight almost constant during storage, independently of the size and color studied. These results are very promising, showing that packaging applied to the coated pansies will reduce weight loss, when compared to the unpackaged pansies.

Regarding dimensions, the packaged pansies maintained constant their dimensions during the 14 days of storage, while the unpackaged coated pansies showed a significant reduction of the width and length values in both colors studied (Figure 4(c) to (f)). The highest impact was observed in the smaller group, with reduction by half: white pansies averagely decreased in width from 3.7 to $1.5 \mathrm{~cm}$ and in length from 3.8 to $1.9 \mathrm{~cm}$.

The water activity values in all cases maintained high $(\geq 0.961)$, slightly higher in the packaged pansies, with values between 0.982 and 0.988 (medium and large sizes, respectively) than in the unpackaged pansies, with values between 0.961 and 0.985 (small and large sizes, respectively).

Color changes of the coated and unpackaged pansies during storage are detailed in Table 2. Significant differences $(p<0.05)$ were detected on individual factors (storage day and size) and their interactions. Between sizes, even though some significant differences were determined in some situations, it was not possible to observe any trend. Moreover, measurement of plain color in the smaller flowers is more difficult, explaining some high standards deviations obtained. Regarding storage time, the only color parameter for which a consistent and significant decrease along time ( 0 and 14 days) was observed for the three sizes groups was the hue $\left(h^{*}\right)$ value in the light part of both pansies, but this behavior was not observed in the dark region. Thus, in general terms, it was concluded that the treatment applied did not affect in great extent the color of pansies in all sizes during storage because no relevant changes were observed on all color parameters.

The color differences $\left(\Delta E^{*}\right)$ of the coated and packaged pansies after 14 days of storage is shown in
Table 3. Total color difference $\left(\Delta E^{\star}\right)$ of the coated and packaged pansies with different sizes after 14 days of storage comparing to fresh ones

\begin{tabular}{llllll}
\hline & \multicolumn{2}{l}{ White } & & \multicolumn{2}{l}{ Violet } \\
\cline { 2 - 3 } \cline { 5 - 6 } Size & White part & Violet part & & Light part & Dark part \\
\hline Small & $1.3 \pm 0.1 \mathrm{a}$ & $4.1 \pm 1.5 \mathrm{a}$ & & $1.4 \pm 0.5 \mathrm{a}$ & $18.3 \pm 10.7 \mathrm{~b}$ \\
Medium & $2.2 \pm 1.5 \mathrm{a}$ & $4.4 \pm 5.9 \mathrm{a}$ & & $8.0 \pm 1.5 \mathrm{~b}$ & $7.2 \pm 2.9 \mathrm{a}$ \\
Large & $8.7 \pm 1.0 \mathrm{~b}$ & $10.9 \pm 0.2 \mathrm{~b}$ & & $7.0 \pm 0.9 \mathrm{~b}$ & $5.2 \pm 3.0 \mathrm{a}$ \\
\hline
\end{tabular}

Notes: Values are expressed as: mean \pm standard deviation. Values with the same letter in same column are not statistically different $(p>0.05)$.

Table 3. Among the white pansies, the larger flowers showed significantly higher values of $\Delta E^{*}$ for both parts (white/violet) than the others two sizes. So, more changes of color occurred in the larger white pansies. On contrary, for the violet pansies, the smaller flowers were the ones presenting a significantly different behavior when compared with the medium and larger flowers. The lowest value of $\Delta E^{*}$ was observed in the light part of the small violet pansies, while its dark parts presented the highest value of $\Delta E^{*}$, with a high standard deviation derived from the difficulty on the measurements, as explained previously.

\section{CONCLUSION}

Edible coating with alginate seemed to have a beneficial impact on the visual appearance of pansies during storage. However, flowers of different sizes and colors have different behaviors. Concerning packaging plus alginate coating, a delay in pansies' weight loss and shrinkage was observed, being high water activity values maintained, independently the color and size. In summary, pansies treated with alginate and packaged represent a cumulative protection, being a very interesting solution to prolong pansies' shelf life, independently their color and size. However, other studies should be performed such as sensory analyses and acceptability tests of consumers to evaluate if these products will have acceptability on the market.

\section{DECLARATION OF CONFLICTING INTERESTS}

The author(s) declared no potential conflicts of interest with respect to the research, authorship, and/or publication of this article.

\section{FUNDING}

The author(s) disclosed receipt of the following financial support for the research, authorship, and/or publication of this article: The authors acknowledge the Portuguese Foundation for Science and Technology (FCT, Portugal) for the financial support provided by the research grant SFRH/BD/95853/ 
2013 and FCT/MEC for the financial support to QOPNA research Unit (FCT UID/QUI/00062/2013), through national funds and when applicable co-financed by the FEDER, within the PT2020 Partnership Agreement and REQUIMTE through the Project PEst/UID/QUI/50006/ 2013. The authors are also grateful to the Foundation for Science and Technology (FCT, Portugal) and FEDER under Programme PT2020 for financial support to CIMO (UID/AGR/00690/2013).

\section{REFERENCES}

Amanatidou A, Slump RA, Gorris LGM and Smid EJ. (2000). High oxygen and high carbon dioxide modified atmospheres for shelf life extension of minimally processed carrots. Journal of Food Science 65: 61-66.

Alboofetileh M, Rezaei M, Hosseini H and Abdollahi M. (2014). Effect of nanoclay and cross-linking degree on the properties of alginate-based nanocomposite film. Journal of Food Processing and Preservation 38: 1622-1631.

Alvarez MV, Ponce AG and Moreira MR. (2013). Antimicrobial efficiency of chitosan coating enriched with bioactive compounds to improve the safety of fresh cut broccoli. LWT - Food Science and Technology 50: 78-87.

Ansorena MR, Marcovich MR and Roura SI. (2011). Impact of edible coatings and mild heat shocks on quality of minimally processed broccoli (Brassica oleracea L.) during refrigerated storage. Postharvest Biology and Technology 59: 53-63.

Cevallos JC and Reid MS. (2000). Effects of temperature on the respiration and vase life of Narcissus flowers. In: SHS Acta Horticulturae 517: XXV International Horticultural Congress, Part 7: Quality of Horticultural Products. DOI: 10.17660/ActaHortic.2000.517.42.

Conca KR and Yang TCS. (1993). Edible food barrier coatings. In: Ching C, Kaplan D and Thomas D (eds) Biodegradable Polymers and Packaging. Lancaster, PA: Technomic Publishing Co., Inc, pp. 357-369.

Contreras-Oliva A, Pérez-Gago MB and Rojas-Argudo C. (2012). Effects of chitosan coatings on physicochemical and nutritional quality of clementine mandarins cv. 'Oronules'. Food Science and Technology International 18(4): 303-315.

Fisher LG and Wong P. (1972). Method of forming an adherent coating on foods. Patent 3,676,158, USA, 2011.

Gamsjaeger S, Baranska M, Schulz H, Heiselmayer P and Musso M. (2011). Discrimination of carotenoid and flavonoid content in petals of pansy cultivars (Viola $\times$ wittrockiana) by FT-Raman spectroscopy. Journal of Raman Spectroscopy 42: 1240-1247.

Hershko V and Nussinovitch A. (1998). Relationships between hydrocolloid coating and mushroom structure. Journal of Agricultural and Food Chemistry 46: 2988-2997.

Kelley KM, Cameron AC, Biernbaum JA and Poff KL. (2003). Effect of storage temperature on the quality of edible flowers. Postharvest Biology and Technology 27: 341-344.

Li J, Yan J, Cao J, Zhao Y and Jiang W. (2012). Preventing the wound-induced deterioration of Yali pears by chitosan coating treatments. Food Science and Technology International 18(2): 123-128.

Lin D and Zhao Y. (2007). Innovations in the development and application of edible coatings for fresh and minimally processed fruits and vegetables. Comprehensive Reviews in Food Science and Food Safety 6: 60-75.

Meneghel RFA, Benassi MT and Yamashita F. (2008). Revestimento comestível de alginato de sódio para frutos de amora-preta (Rubus ulmifolius). Semana: Ciência Agrária (Londrina) 29: 609-618.

Moldão-Martins M, Beirão-da-Costa SM and Beirão-daCosta ML. (2003). The effects of edible coatings on postharvest quality of the "Bravo de Esmolfe" apple. European Food Research and Technology 217: 325-328.

Moreira MR, Roura SI and Ponce A. (2011). Effectiveness of chitosan edible coatings to improve microbiological and sensory quality of fresh cut broccoli. LWT - Food Science and Technology 44: 2335-2341.

Nussinovitch A and Hershko V. (1996). Gellan and alginate vegetable coatings. Carbohydrate Polymers 30(2-3): 185-192.

Rop O, Mlcek J, Jurikova T, Neugebauerova J and Vabkova J. (2012). Edible flowers - A new promising source of mineral elements in human nutrition. Molecules 17: 6672-6683.

Tay SL and Perera CO. (2004). Effect of 1-Methylcyclopropene treatment and edible coatings on the quality of minimally processed lettuce. Journal of Food Science 69: 131-135.

Trivellini A, Gordillo B, Rodríguez-Pulido FJ, Borghesi E, Ferrante A, Vernieri P, et al. (2014). Effect of salt stress in the regulation of anthocyanins and color of Hibiscus flowers by digital image analysis. Journal of Agricultural and Food Chemistry 62: 6966-6974.

Vukics V, Kery A and Guttman A. (2008). Analysis of polar antioxidants in heartsease (Viola tricolor L.) and garden pansy (Viola $\times$ wittrockiana Gams.). Journal of Chromatographic Science 46: 823-827. 